\title{
POST-HOC SEGMENTATION OF AIRLINE MARKET IN SERBIA USING CBC AND PAM
}

\author{
Anis Ivanović ${ }^{1}$, Nataša Bojković ${ }^{2}$, Marijana Petrović ${ }^{3}$ \\ 1,2,3 University of Belgrade, Faculty of Transport and Traffic Engineering, 11010 Belgrade, Serbia \\ Received 24 February 2020; accepted 14 March 2020
}

\begin{abstract}
Choice Based Conjoint (CBC) Analysis identifies customer preferences according to the key characteristics of the service, providing the opportunity to create an optimal offer. Since preferences are measured at the individual level, it is possible to gain insight into the heterogeneity of the market and to segment it using cluster analysis methods. This paper demonstrates how CBC and Partitioning Around Medoids (PAM) can be used to segment the passenger air transport market. An empirical example relates to a case study of air transport in Serbia.
\end{abstract}

Keywords: segmentation of the market, Choice Based Conjoint (CBC), Discrete Choice Modeling (DCM), clustering, Partitioning Around Medoids (PAM).

\section{Introduction}

In order to operate successfully in a competitive environment, an airline must be oriented towards its end customer, although it is aware of the fact that the customer needs are different and it is impossible to fully meet all their market requirements. Therefore, it is advisable to divide the market, select the appropriate segments and design suitable strategies for these segments.

Market segmentation is the beginning of developing a successful marketing strategy. By segmenting the market, the airline operates more efficiently in the target segment and directs services and communication to customers, meets their needs in the best way and maximizes the benefits. Also, by focusing on the market segments the airline faces fewer competitors compared to dealing with the overall market for a particular service.
The two main approaches to market segmentation are (Freathy \& O'Connell, 2000; Allenby et al., 2002):

- a priori (ex ante) segmentation; and

- posthoc (ex post) segmentation.

The first approach is based on the identification of broad-based, easily identifiable segments that are classified at the macro level, i.e. involves the division of markets according to predefined criteria (e.g. education, age, gender, earnings, culture, etc.) without using the results of primary research. This approach divides the large market into a number of smaller market segments.

In the second approach, primary market research is used to collect segmented variables, and segments are defined when relevant management data is collected and analyzed, i.e. individuals are grouped

${ }^{1}$ Corresponding author: a.ivanovic@sf.bg.ac.rs 
by relevant "micro-segments". With this approach, individual customers are grouped into homogeneous groups based on their answers to questions about attitudes or behavior. A large number of multivariate analytical techniques can be used for posthoc segmentation.

By choosing the most promising segment and knowing the needs of the passengers, the airline more successfully creates the right combinations of services for each segment and adjusts supply to demand. For example, business travelers may require a larger number of daily flights, accuracy, a large number of destinations, good connection to the airport and seat availability. The airline should adapt its services to the selected segment.

In this paper, we use a post hoc approach for the segmentation of air passenger market. For primary market research, we use the Choice Based Conjoint (CBC) analysis that determines consumers' preferences for key service features and enables the creation of an optimal offer. After collecting and analyzing relevant data, we segment the market based on consumer preferences using non-hierarchical cluster analysis, the Partitioning Around Medoids (PAM) method. PAM is an implementation of the K-medoid algorithm, which means that medoid (representative entity/respondent /consumer) is the center of each cluster/ segment. Medoid can be defined as a cluster object whose average length difference from all objects in the group is minimal, i.e. most commonly the centrally located point in the cluster. The algorithm groups the data set of $n$ objects into clusters (partitions) $k$ with the number of $k$ clusters assumed a priori known $(k \leq n)$. If $\mathrm{k}$ is unknown, it can be determined by silhouette method. An object is assigned to the closest cluster based on measuring the distance between the object and the center of the cluster (starts from the initial set of medoids and iteratively replaces one of the medoids by non-medoids if the minimum average length difference from all objects in the group is improved). Then the algorithm iteratively improves the variation within the cluster by computing the new cluster center using the objects assigned to the cluster in the previous iteration. After the cluster centers are updated, all objects are added to the new cluster centers. Iterations continue until the clusters formed in the current circle are the same as those formed in the previous circle. PAM is simple and easy to apply, and the algorithm is fast and converges at a fixed number of iterations. However, in order for the airline to gain a lasting competitive advantage and secure a strong market position, it is necessary, in addition to the strategy of segmentation and differentiation, to choose an optimal positioning strategy.

In order to determine the service preferences of the respondents in passenger air transport, identification of key attributes (characteristics) was carried out and then a survey was conducted in which the respondents validly answered 355 survey questionnaires with Conjoint questions.

The paper is organized as follows; Section 2 provides an overview of the literature on the air transport segmentation market and Section 3 presents the methodologies applied in this research. An analysis of the research results is presented in Section 4. Consumer preferences of predefined segments (a priori segmentation) are presented in Section 5. Segmentation based on consumer preferences (post hoc segmentation) is presented in Section 6. Concluding considerations with 
directions for further research are presented at the end of the paper, in Section 7.

\section{Literature Review}

Early studies of the air transport segmentation market were given in Bruning et al. (1985) and Robles \& Sarathy (1986). In the first paper, Bruning et al. (1985), two market segments of passenger air carriers were identified by an a priori approach: national (main) and regional (commuter). The authors of the paper focus on market factors and behavioral factors that are involved in selecting the type of an airline. The data were analyzed using linear discriminant analysis. The authors concluded that airline passengers could be successfully segmented by environmental, demographic and personal factors. However, the significance of this study is diminished due to the fact that commuter air carriers no longer exist in their original form, i.e. they have evolved into national and regional carriers. In the second paper, Robles \& Sarathy (1986), two different market segments of airplanes for commuter air carriers were identified by a post-hoc approach using a hierarchical cluster analysis based on survey questionnaire data from 48 airlines. The implications of these two clusters on the marketing strategies of the commuter aircraft manufacturers are discussed, with particular emphasis on fleet characteristics and decision making processes for aircraft purchases in each segment.

Freathy \& O'Connell (2000) deal with the segmentation of airport customers by type of flight: domestic versus international; short haul versus long haul; business versus leisure. The authorities use this form of $a$ priori segmentation to determine the most appropriate combination of commercial airport space users, i.e. arrange and manage commercial space in the best interests of stakeholders. Airport entrepreneurs also use segmentation strategies based either on $a$ priori or post hoc principles in their businesses.

In Teichert et al. (2008), micro-level segmentation is presented using detailed data on consumer behaviors and their specific expectations. The main objective is to better understand consumer behavior and to adapt services more successfully. The authors, using the model of latent modeling class, apply data from the aforementioned studies of airline passenger preferences. They distinguish between an a priori approach (without using primary research results) and a posteriori or post-hoc approach (with the collecting and analyzing of relevant data for management). The data were collected using a Conjoint choice-based research. In this study, seven two-level attributes were used for each attribute. The authors concluded that segmentation with greater differences between airline service customers was required and they suggested five different passenger segments according to their preferences. Segment profiles reveal three potential ways to specialize a service by offering: comfort, efficiency, and price orientation. Comfort service is oriented towards high-level position managers who travel by plane for business reasons, as well as wealthy travelers who travel in their leisure time. Efficiency service is important for business travelers in very high-ranking positions who travel by plane every other day. Price-oriented service is interesting to a wider range of customers and is directed at entrepreneurs, as well as middle-ranking, younger managers and retirees.

Chao et al. (2013) focused on the importance of the air cargo market segmentation 
covering tariffs, cargo tracking and accuracy, as well as the service attributes according to the requirements of the air freight forwarders. They reduced the variables by factor analysis and extracted a load factor greater than 0.5. Thus, a one-way ANOVA was used to examine key attributes that show a significant difference between service segments. The authors used the survey questionnaire as a data collection method and cluster analysis for market segmentation. The survey questionnaire was based on the papers of various authors and interviews with 10 experts in the field of cargo airline services research in Taiwan. Principal Component Analysis (PCA) was used with the factor analysis by varimax rotation to reduce the 36 service attributes of airline cargo transportation and to identify the key factors. The results showed that there were six key service factors: reliability, promptness, empathy, comfort, added value and customization. Each service had a load factor value greater than 0.5 . The service attributes were further classified by a post-hoc approach into three markets according to cargo airline users oriented toward: professional services, empathy and express shipping services.

Chen et al. (2016) deal with the preferences related to ecology. This study explores whether there is an ecology-oriented market sub-segment (niche) in Taiwan's airline market. Based on a survey of 416 airline customers, the authors of the paper segmented customers according to their environmental behavior using factor and cluster analysis. Post-hoc cluster analysis shows that five factors of environmental behavior (green consumption, recycling, political participation, economic factor and public transport) affect significant differences between the three clusters (the environmentally indifferent, the enlightened environmentalists and the active environmentalists). Clusters are further profiled in relation to socio-demographic and behavioral characteristics, as well as attitude characteristics. The results suggest that the green consumer segment is large enough to justify the attention of airlines, while enlightened and active environmentalists representing the most promising target market. The Internet, TV programs, newspapers and magazines are the main sources of environmental information.

Most of the papers on airline market segmentation apply traditional a priori segmentation based on socio-demographic and similar characteristics, while a minority of them deal with post hoc preference segmentation. In this paper we strive to fill this void by using CBC and PAM to form characteristic Serbian airline customer clusters based on the uniformity of their preferences. Air travel service providers can more easily determine their operational priorities in the market when they are aware of customer expectations. The CBC and PAM approach helps airlines implement market specificities into service models. An example of a study that combines CBC and PAM methods to segment users can be found in Bojković et al. (2019). This paper proposes an a priori (ex ante) analysis that aims to discover how students experience the possibility of personal mobility in an area where car sharing is underdeveloped. University of Belgrade students were asked to state their preferences regarding the combination of attributes and service levels used in current practice. The aforementioned preference survey and $\mathrm{CBC}$ analysis considered preferences for certain service attributes, while the latter preferencebased segmentation was obtained by the PAM method. 
The added value of our approach lies in the ability to accurately perceive and understand more deeply the user segments free from ambivalent assumptions about underlying socio-economic conditions.

\section{Methodology of Research}

The research was conducted in five steps. In the first step, a list of key attributes and their levels is created. In the second step, an experiment plan is made. In the third step, the data were collected through a questionnaire. In the fourth step, the data collected were processed by the statistical package SPSS 21.0. In the fifth step, the validity of the results was checked. These steps will be explained in more detail below.

\section{Step 1. Creating a List of Key Attributes and Their Levels}

In the first phase of the research, key attributes and their levels were identified, i.e. characteristics that differentiate an airline company on a single route. The selection of key attributes and their levels is based on a "brainstorming" technique applied to a group of experts (practitioners and researchers) in air transport. The list of key attributes has been refined and modified through a literature review (Doganis, 2002; Lu \& Tsai, 2004; Albers et al., 2005; Hess et al., 2006; Hess, 2008 and Collins et al., 2010) and verified through a survey questionnaire. Preliminary research was conducted using the traditional "paper and pencil" method in December 2018. All of those respondents expressed their preferences for each of the 13 offered combinations of passenger air traffic attributes on a Likert scale from 1 to 5 , where 1 means "not important/ I will not choose definitely" and 5 means "very important/I will definitely choose". The sample consisted of 40 respondents who were asked to rank 13 criteria on a scale of 1 to 5 when choosing a flight to a particular destination. Appendix A provides the layout of the survey questionnaire.

Table 1 presents the results of the preliminary survey with a list of 13 key attributes and their mean scores, as well as the standard deviations (std. dev.). The respondents gave the highest score to the attributes: directflight to destination, flights punctuality, and cheap flight ticket.

\section{Table 1}

Preliminary Research Results

\begin{tabular}{|c|l|c|c|}
\hline No. & Service Attributes & Means & Std. dev. \\
\hline 1 & Direct flight to destination & 4.25 & 0.93 \\
\hline 2 & Flights punctuality & 4.25 & 0.81 \\
\hline 3 & Cheap flight ticket & 4.10 & 1.17 \\
\hline 4 & Airline safety reputation & 3.88 & 1.04 \\
\hline 5 & Appropriate take off time & 3.53 & 1.22 \\
\hline 6 & Speed of check-in & 3.48 & 1.06 \\
\hline 7 & Size space legs & 2.98 & 1.39 \\
\hline 8 & Free food and drinks & 2.80 & 1.36 \\
\hline 9 & Number of daily flights & 2.73 & 1.28 \\
\hline 10 & Airline terminal & 2.73 & 1.04 \\
\hline 11 & Seat width & 2.70 & 1.22 \\
\hline 12 & Possibility to gain frequent flyer miles/points & 2.23 & 1.29 \\
\hline 13 & Airline name & 2.20 & 1.09 \\
\hline
\end{tabular}


In order to get quality results, the number of attributes and their levels should not be too large when conducting $\mathrm{CBC}$ analysis. It is recommended that the maximum number of attributes be 6 when using CBC (Hair et al., 2014, p. 359). In the case of a large number of atributes/levels, the questionnaire would end with many profiles (hypothetical airlines) to be evaluated, leading to unreliable results due to the loss of concentration of the respondents. For this reason, 3 attributes with highest rankes were selected for further analysis: direct flight to destination, flights punctuality, and cheap flight ticket.

After selecting the attributes, they are assigned with levels (Table 2).

Table 2

Key Attributes List and Their Levels

\begin{tabular}{|c|c|c|}
\hline No. & Attributes & Levels \\
\hline 1 & Flight ticket price & 120 EUR, 180 EUR \\
\hline 2 & Direct flight to destination & Direct flight, Connecting flight \\
\hline 3 & Flights punctuality & On time, Delayed \\
\hline
\end{tabular}

\section{Step 2. Experiment Plan}

After selecting the key attributes and their levels, they are combined to form different hypothetical profiles of airlines routes and further evaluated by respondents. In other words, an experiment plan is being made.
The attributes and their levels shown in Table 2 gave a total of 8 possible profiles. Four holdout tasks were added but not used to calculate preferences. Their sole purpose was to check the quality of the obtained results. All 12 hypothetical profiles are presented in Table 3.

Table 3

Generated Profiles List (Orthogonal Experiment Plan)

\begin{tabular}{|c|c|c|c|}
\hline Profiles & Flight Ticket Price & Flights Punctuality & Direct Flight to Destination \\
\hline 1 & 180 EUR & Delayed & Direct flight \\
\hline $2^{*}$ & 180 EUR & On time & Connecting flight \\
\hline 3 & 120 EUR & Delayed & Connecting flight \\
\hline 4 & 180 EUR & On time & Connecting flight \\
\hline $5^{*}$ & 180 EUR & Delayed & Direct flight \\
\hline 6 & 120 EUR & On time & Connecting flight \\
\hline $7^{*}$ & 180 EUR & On time & Direct flight \\
\hline 8 & 180 EUR & On time & Direct flight \\
\hline 9 & 120 EUR & On time & Direct flight \\
\hline 10 & 120 EUR & Delayed & Connecting flight \\
\hline $11^{*}$ & 120 EUR & On time & Delayed \\
\hline 12 & 180 EUR & & flight \\
\hline
\end{tabular}

\section{${ }^{*}$ Holdout tasks}

Considering the above alternatives, it is logical that service 6 is probably the most desirable choice, while service 12 is probably the least desirable choice. Considering the above alternatives, service 6 is probably the most desirable choice, while service 12 
is probably the least desirable choice. The preference for other services is determined by what is important to that person. If we have other information about passengers, e.g. demographic, we can identify market segments for different services. For example, business and leisure passengers have different priorities that the airline can satisfy with its special flight offers.

\section{Step 3. Data Collection}

After the design of the experiment plan, the next phase is to determine the user preferences for the selected profiles. The respondents evaluated the selected profiles using the game of choice method. They were selecting one of the four options offered three times and thus expressed their preferences for each of the 12 offered combinations of services in air passenger transport.

The method of data collection is an important step because of its effect on the validity of data and their use in statistical processing. In this research, data were collected through an electronic survey that was made on "Google Docs", and then the link was forwarded to the respondents via email or social networks ("Facebook", “Twitter"). This method of data collection was chosen for several reasons:

1) Online surveys are much cheaper than the traditional "pen-and-paper" method;

2) Online survey can be filled by a large number of respondents at the same time;

3) The survey questionnaire is available to a large number of people.

In addition to Conjoint questions, the survey also included some basic demographic questions, as well as those related to respondents' views on air passenger traffic. Appendix B provides the layout of the survey questionnaire.
To determine the respondents preferences for air passenger services, a survey was conducted between December 12, 2018 and January 23, 2019. The sample consisted of 369 subjects. Subsequent verification removed 14 survey questionnaires so that the total number of valid survey questionnaires was reduced to 355 .

\section{Step 4. Data Processing and Validation of Results}

After collecting data on the individual preferences of the respondents, an analysis of the answers is made. Statistical package SPSS 21.0 was used for data analysis. The parameters were estimated for each respondent in the sample (individual preferences) as well as for the entire sample (average preferences).

In the survey questionnaire containing Conjoint questions, the respondents may provide some inconsistent answers. It is therefore a challenge to assess whether these inconsistencies are large enough to jeopardize the validity of the answers. In this research, two approaches were used to measure the validity of the results: 1 ) internal consistency of preferences, and 2) consistency with theoretical predictions.

Internal consistency was measured in three ways. First, Pearson's (Pearson's R) and Kendall's coefficient (Kendall's tau) were used to measure the correlations between observed and expected preferences. Secondly, Kendall's coefficient was used to verify the validity of the 4 holdout profiles. The respondent rated control profiles that were not used to calculate preferences, i.e. usefulness. Instead, they used to calculate the correlation between the input and estimated preferences of 
these profiles to verify the validity of the obtained utility.

As a third way, the monotonicity test was used to show greater or less preferences of the respondents at some attribute of a service. For example, it can be assumed that the respondent prefers a higher supply of passenger air transport and a lower cost of service. Theoretical validity was investigated on the basis of positive or negative sign of the estimated parameters.

\section{Research Results Analysis}

Valid survey questionnaires with detailed demographics data of 355 respondents are presented in Table 4 . The mean age of the respondent was 41.81 years $(S D=11.67)$. The youngest respondent had been 16 years old and the oldest one 72 years old.
The survey showed that 106 (29.9\%) of the respondents fly frequently (multiple times a year), 197 (55.5\%) occasionally, while $52(14.6 \%)$ have never flown an airplane. Respondents had given their reasons for rarely or never flying by airplane, whereby they were able to choose one or more reasons, but they could also chose not to gave an answer. 98 (27.6\%) respondents choosed "Financial reasons" and 48 (13.5\%) of them gave "Lack of free time".

The results of the Choice Based Conjoint (CBC) Analysis related to the preferences of the respondents according to the key characteristics of the services in passenger air transport are shown in Table 5. The second column shows the average values of the significance of the attributes, while the column "Partial utility" shows the utility levels of each attribute at the aggregate level.

Table 4

The Respondents Demographic Structure

\begin{tabular}{|l|l|c|c|}
\hline & & Number & Percentage (\%) \\
\hline \multirow{4}{*}{ Sex } & Male & 198 & $55.8 \%$ \\
\cline { 2 - 4 } of my Household & Female & 157 & $44.2 \%$ \\
\cline { 2 - 4 } & Under 20000 din. & 11 & $3.1 \%$ \\
\cline { 2 - 4 } & $20000-40000$ din. & 77 & $21.7 \%$ \\
\cline { 2 - 4 } & $40000-80000$ din. & 186 & $52.4 \%$ \\
\cline { 2 - 4 } & $80000-160000$ din. & 49 & $13.8 \%$ \\
\cline { 2 - 4 } & Over 160000 din. & 32 & $9.0 \%$ \\
\hline \multirow{5}{*}{ My Educational Level } & Elementary school & 2 & $0.6 \%$ \\
\cline { 2 - 4 } & High school & 57 & $16.1 \%$ \\
\cline { 2 - 4 } & College & 58 & $16.3 \%$ \\
\cline { 2 - 4 } & Faculty & 129 & $36.3 \%$ \\
\cline { 2 - 4 } & Master & 87 & $24.5 \%$ \\
\cline { 2 - 4 } & Doctorate & 22 & $6.2 \%$ \\
\hline \multirow{5}{*}{ Employment Status } & Pupil & 2 & $0.6 \%$ \\
\cline { 2 - 4 } & Student & 14 & $3.9 \%$ \\
\cline { 2 - 4 } & Employed & 323 & $91.0 \%$ \\
\cline { 2 - 4 } & Unemployed & 6 & $1.7 \%$ \\
\cline { 2 - 4 } & Pensioner & 10 & $2.8 \%$ \\
\hline
\end{tabular}


A constant whose value is 0.32 is used to calculate the total usefulness of each profile. The value 0.819 of Pearson's coefficient indicates that the obtained results have a high level of significance and we can conclude that they are of high quality. The value 0.571 of Kendall's correlation coefficient indicates a satisfactory level of correlation between input and estimated preference. Kendall's correlation coefficient for the 4 holdout profiles has a value of 0.913 , which additional shows that high quality data has been obtained.

Passengers will always make compromises when evaluating a service. The passenger may like the comfort and arrival time of a particular flight, but he/she can still refuse the purchase due to cost. In this case, costs have a high level of partial utility. The partial utility can be defined as a number that represents the value that passengers give to an attribute. In other words, it represents the relative value of the attribute. The low partial utility indicates lower value for the passenger, while the high partial utility indicates higher value for the passenger. Plus or minus signs of the partial utility is also in line with expectations. For example, a negative sign indicates that the respondent does not prefer connecting flights (partial utility is - 0.148 ) or delayed flights (partial utility is -0.147). The respondents showed expected behavior for all other attributes where the most desirable level had the highest utility. These results can be considered as an indication of the theoretical validity of the survey questionnaire, i.e. to what extent the obtained results are in line with expectations.

Table 5

The Summary Results of the Respondents' Preferences at the Aggregate Level

\begin{tabular}{|c|c|c|c|}
\hline Attributes and their Levels & Attribute Significance (\%) & Partial Utility & Std. Error \\
\hline Flight Ticket Price & 33.070 & & \\
\hline 120 EUR & & 0.032 & 0.074 \\
\hline 180 EUR & & -0.032 & 0.074 \\
\hline Flights Punctuality & 28.761 & & \\
\hline On time & & 0.147 & 0.074 \\
\hline Delayed & & -0.147 & 0.074 \\
\hline Direct Flight to Destination & 37.606 & & \\
\hline Direct flight & & 0.148 & 0.074 \\
\hline Connecting flight & & -0.148 & 0.074 \\
\hline \multicolumn{4}{|c|}{\begin{tabular}{l|l} 
Constant $=0.318$ & \\
\end{tabular}} \\
\hline \multicolumn{4}{|c|}{ Correlations between observed and estimated preferences } \\
\hline & Value & Sig. & \\
\hline Pearson's R & 0.819 & 0.006 & \\
\hline Kendall's tau & 0.571 & 0.024 & \\
\hline Kendall's tau for Holdouts & 0.913 & 0.035 & \\
\hline
\end{tabular}

As can be seen from Table 5, the most significant attribute at the level of the whole sample is "Direct flight to destination", whose average significance at the aggregate level is $37.6 \%$. The attributes of "Flight ticket price" (33.07\%) and "Flights punctuality" (28.76\%) have a slightly lower significance at the aggregate level. 
5. Consumer Preferences of Predefined Segments - a priori Segmentation

The users can be grouped into predefined segments, based on sociodemographic data and personal attitudes, that is known as $a$ priori segmentation. Within the predefined segments it is possible to identify subsegments taking into account certain characteristics of the respondents. In this research, a priori segmentation based on the criterion of how often the respondents fly by plane was performed. As stated earlier, the largest number of the respondents, namely 197 of them (55.5\%), occasionally fly by plane, 106 (29.9\%) frequently fly by plane (several times a year), while only 52 (14.6\%) have never flown a plane.

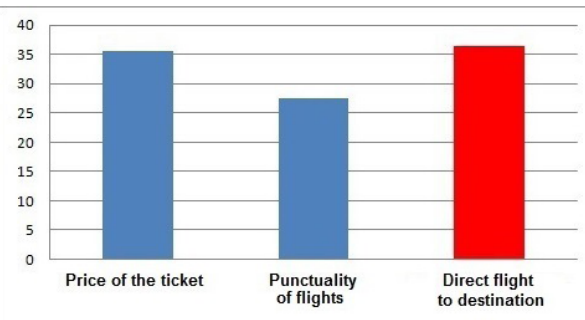

a) Occasionally fly by plane

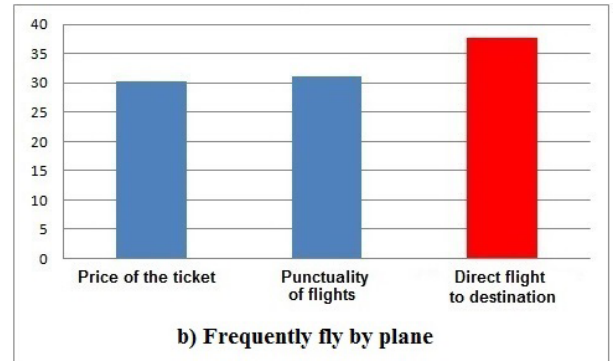

b) Frequently fly by plane

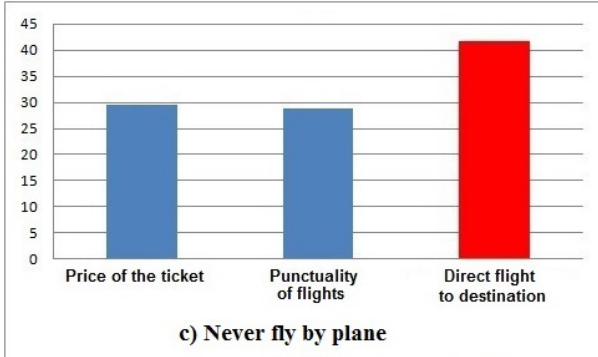

Fig. 1.

Average Significance of Attributes by Segments: a) Occasionally Fly by Plane, b) Frequently Fly by Plane and c) Never Fly by Plane

Figure 1 shows the differences in the significance of the attributes for each of the predefined segments, while Table 6 shows the partial utility of the attribute levels for each of these segments, as well as the statistical indicators of the quality obtained data (Pearson's and Kendall's coefficient) whose high values indicates great significance and reliability of results. 
Table 6

The Attribute Level Partial Significance for Predefined Segments

\begin{tabular}{|c|c|c|c|}
\hline \multicolumn{4}{|c|}{ Segments } \\
\hline Attributes and their Levels & $\begin{array}{c}\text { Never } \\
\text { Fly by Plane } \\
52(14.6 \%)\end{array}$ & $\begin{array}{c}\text { Frequently } \\
\text { Fly by Plane } \\
106(29.9 \%)\end{array}$ & $\begin{array}{l}\text { Occasionally } \\
\text { Fly by Plane } \\
197(55.5 \%)\end{array}$ \\
\hline Flight Ticket Price & $29.5 \%$ & $30.3 \%$ & $35.5 \%$ \\
\hline 120 EUR & 0.026 & 0.020 & 0.039 \\
\hline 180 EUR & -0.026 & -0.020 & -0.039 \\
\hline Flights Punctuality & $28.7 \%$ & $31.0 \%$ & $27.5 \%$ \\
\hline On time & 0.151 & 0.159 & 0.140 \\
\hline Delayed & -0.151 & -0.159 & -0.140 \\
\hline Direct Flight to Destination & $41.8 \%$ & $37.7 \%$ & $36.4 \%$ \\
\hline Direct flight & 0.132 & 0.159 & 0.146 \\
\hline Connecting flight & -0.132 & -0.159 & -0.146 \\
\hline Constant & 0.315 & 0.317 & 0.324 \\
\hline Pearson's R & 0.855 & 0.827 & 0.804 \\
\hline Kendall's tau & 0.618 & 0.667 & 0.571 \\
\hline Kendall's tau for 4 Holdouts & 0.800 & 0.913 & 0.913 \\
\hline
\end{tabular}

The results indicate that "Direct flight to destination" is the most important for all three segments of the respondents. The segment of the respondents that "frequently" fly by plane the significance of "Flight Accuracy" was in the second place, while the segments of the respondents that "occasionally" fly by plane and "never" fly by plane significance of "Price" was in the second place.

Segmentation of the air transport market in Serbia based on the consumer preferences of predefined segments (a priori) has shown that passengers will not choose airlines that are known for flight delays and flight cancellations. In addition to the Flights punctuality that is important to the passengers:
- $70.1 \%$ of the passengers would use connecting flights if their ticket price is more favorable;

- $\quad 29.9 \%$ of the passengers would pay a higher ticket price for a direct flight to their destination.

\section{Segmentation Based on Consumer Preferences - post hoc Segmentation}

Using the individual preferences (partial utility) of the respondents, obtained through the research, post hoc segmentation was performed. K-medoid cluster analysis, the PAM partitioning algorithm, within MATLAB R2018a and RStudio 1.1.463 was used for segmentation. Figure 2 and Figure 3 provide the segment computation in MATLAB R2018a and RStudio 1.1.463 software. 

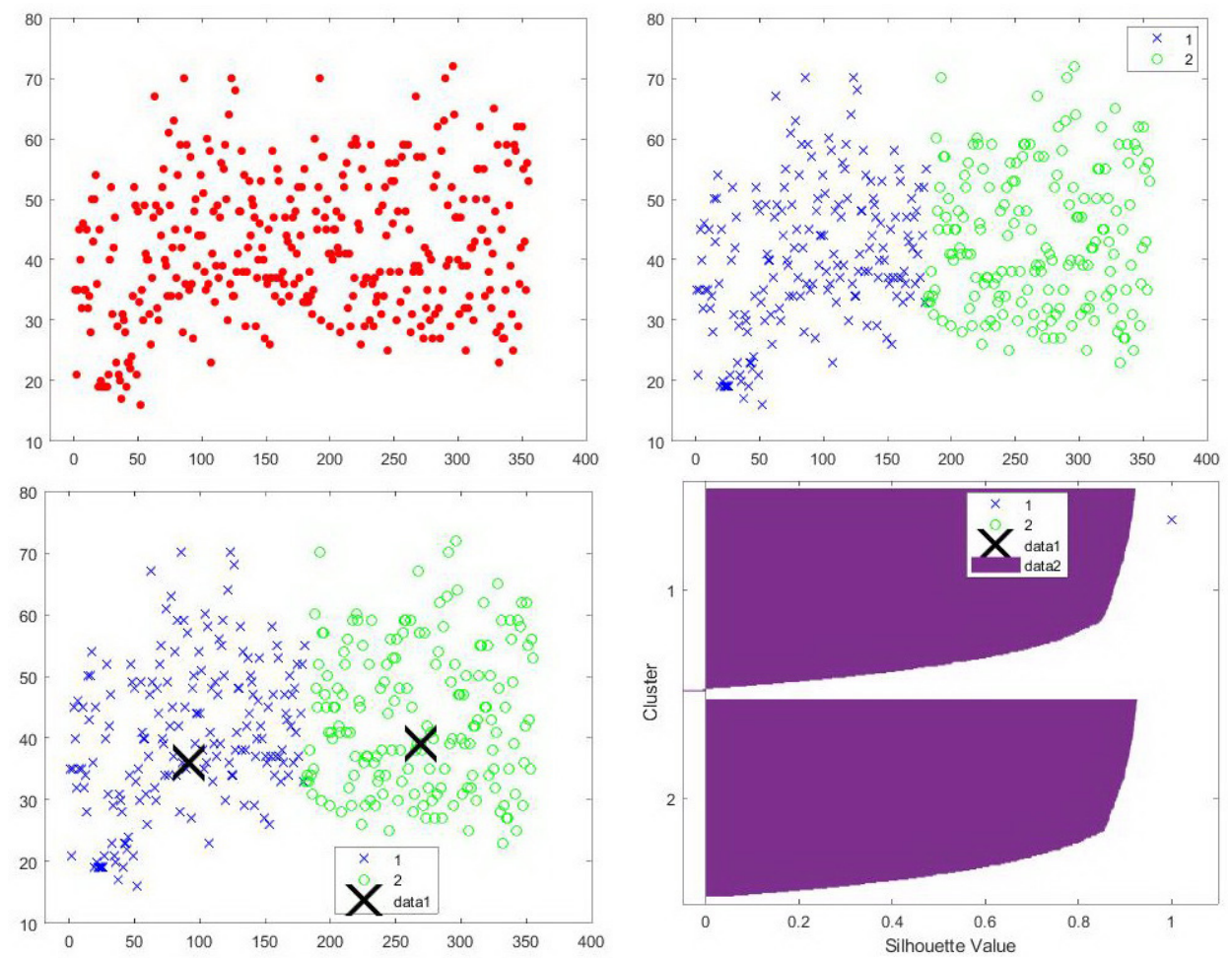

Fig. 2.

Segment Computation in MATLAB R2018a Software

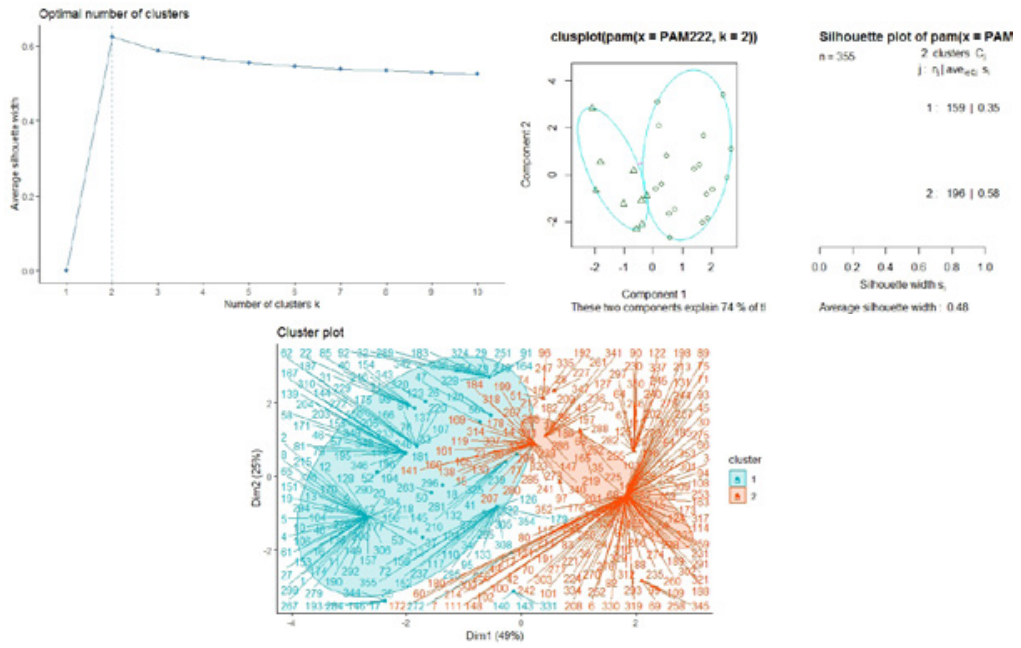

Fig. 3.

Segment Computation in RStudio 1.1.463 Software 
Two segments were isolated, and the number of the users in each segment, as well as the average partial utilities of the attribute level are given in Table 7 . The relative significance of the attributes per segment is shown in
Figure 4 and Figure 5. Two segments were selected because the silhouette method indicated that this was the optimal number of segments for the partial utility of the respondents obtained by $\mathrm{CBC}$ analysis.

\section{Table 7}

Segments and Their Preferences

\begin{tabular}{|c|c|c|c|}
\hline \multirow{2}{*}{ Attributes } & Attributes Levels & $\begin{array}{c}\text { Segment 1 } \\
\mathbf{n}=\mathbf{1 5 9}(\mathbf{4 4 . 7 9 \% )}\end{array}$ & $\begin{array}{c}\text { Segment 2 } \\
\mathbf{n}=\mathbf{1 9 6}(\mathbf{5 5 . 2 1} \%)\end{array}$ \\
\hline \multirow{3}{*}{ Flight Ticket Price } & & $\mathbf{5 3 . 8 2} \%$ & $\mathbf{2 0 . 8 1 \%}$ \\
\cline { 2 - 4 } & 120 EUR & 0.216 & -0.118 \\
\cline { 2 - 4 } & 180 EUR & -0.216 & 0.118 \\
\hline \multirow{3}{*}{\begin{tabular}{c} 
Flights Punctuality \\
\cline { 2 - 4 }
\end{tabular}} & On time & $\mathbf{3 6 . 2 0} \%$ & $\mathbf{2 6 . 2 1 \%}$ \\
\cline { 2 - 4 } & Delayed & 0.145 & 0.149 \\
\hline \multirow{3}{*}{$\begin{array}{c}\text { Direct Flight to } \\
\text { Destination }\end{array}$} & & -0.145 & -0.149 \\
\cline { 2 - 4 } & Direct flight & $\mathbf{9 . 9 8 \%}$ & $\mathbf{5 2 . 9 8 \%}$ \\
\cline { 2 - 4 } & Connecting flight & -0.040 & 0.300 \\
\hline
\end{tabular}

The two medoids (center points) that were used in the Partitioning Around Medoids (PAM) algorithm are presented in Table 8:

Table 8

The Two Midoids (Center Points)

\begin{tabular}{|c|c|c|c|c|c|c|c|}
\hline Medoids & ID & EUR120 & EUR180 & On time & Delayed & Direct & Connecting \\
\hline$[1]$ & 1 & 0.75 & 0.0 & 0.5 & 0.25 & 0.25 & 0.5 \\
\hline$[2]$ & 353 & 0.25 & 0.5 & 0.5 & 0.25 & 0.75 & 0.0 \\
\hline
\end{tabular}

\subsection{Characteristics of the "Price Sensitive Passengers" Segment}

The first segment includes 159 users, representing $44.79 \%$ of the total sample. For members of this segment, the Flight ticket price is crucial when choosing a particular airline, which can be seen in Figure 4 (attribute significance is $53.82 \%$ ). The Flights punctuality is also important to them (attribute significance is $36.2 \%$ ) and they will not choose airlines that are known for flight delays and flight cancellations. 


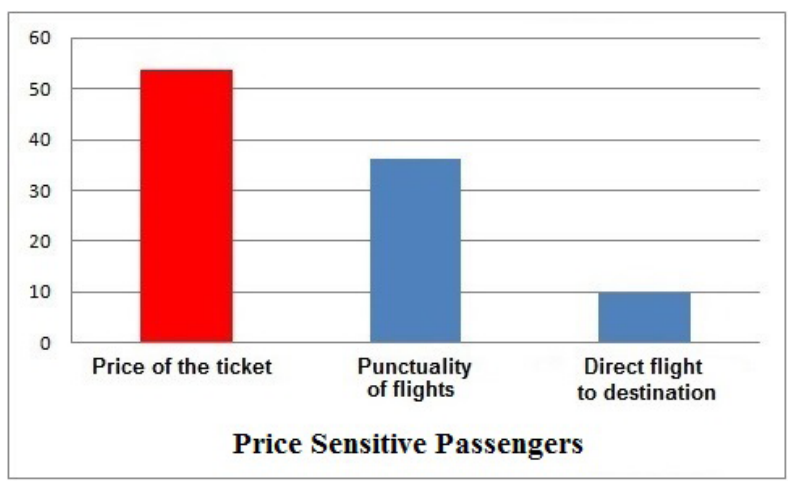

Fig. 4.

The Relative Significance of the Attribute for the Segment "Price Sensitive Passengers"

\subsection{Characteristics of the "Time Sensitive Passengers" Segment}

The second segment is slightly larger and includes 196 users, that represents $55.21 \%$ of the total sample. It is made up of the respondents choosing Direct flight to destination as the most important atribute, as can be seen in Figure 5 (attribute significance is 52.98\%). Flight ticket price is the least important to them.

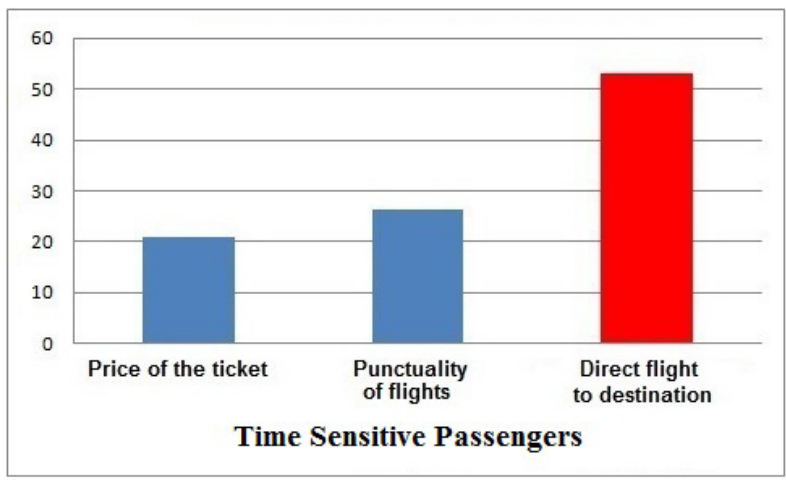

Fig. 5.

The Relative Significance of the Attribute for the Segment "Time Sensitive Passengers"

Segmentation of the air transport market in Serbia based on the consumer preferences (post hoc) has shown that passengers will not choose airlines that are known for flight delays and flight cancellations. In addition to the Flights punctuality that is important to the passengers:
- $44.79 \%$ of the passengers would use connecting flights if their ticket price is more favorable;

- $\quad 55.21 \%$ of the passengers would pay a higher ticket price for a direct flight to their destination. 


\section{Conclusion}

This paper extends the existing knowledge of airline services in Serbia. In addition to showing the priorities (preferences) of airline service users, the research proposes distinctive customer clusters according to their preferences. We combine Choice Based Conjoint (CBC) analysis i.e. Discrete Choice Modeling (DCM) with non-hierarchical cluster analysis to get user priorities (preference). The customer preference structure assists airlines in creating services and deciding on marketing activities.

By using post hoc (ex post) segmentation based on consumer preferences in the air transport market in Serbia, two segments can be observed. In the first segment $(55,21 \%$ of the Serbian air traffic market) passengers are prepared to pay a higher price for a direct flight to their destination. In the second segment (44.79\% of the Serbian air transport market) passengers are ready to use connecting flights if their ticket price is more favorable. Flight accuracy is important for passengers in both segments.Using post hoc segmentation data, it is possible to propose a marketing strategy for both segments, as well as the strategies for positioning the airline on the market. However, as the airline's business is motivated by long-term survival at the market, in addition to maximizing business profits over the long term that requires some changes and adjustments to the airline, the question is how would passenger preferences change if the airline transforms some characteristics of the business. The answer to this question can be obtained by simulating the market i.e. "What If Analysis". For the management of each airline, a very important step in the Conjoint analysis is the creation of a simulation model and the simulation of the market itself. Market simulations can reveal hidden effects that can affect passengers' preferences for airline services, that cannot be determined using average partial benefits. Simulation models also provide the ability to transform unclear partial utility into a market segment, that is much more useful for managers. This is the subject of our future research.

\section{References}

Albers, S.; Koch, B.; Ruff, C. 2005. Strategic alliances between airlines and airports - theoretical assessment and practical evidence, Journal of Air Transport Management 11: 49-58.

Allenby, G.; Fennell, G.; Bemmaor, A.; Bhargava, V.; Christen, F.; Dawley, J.; Sawyer, A. 2002. Market segmentation research: beyond within and across group differences, Marketing Letters 13(3): 233-243.

Bojković, N.; Jeremić, V.; Petrović, M.; Tica, S. 2019. Preferences for car sharing service attributes among university students: Evidence from an emerging market, Journal of East European Management Studies (JEEMS) 24(4): 635-652.

Bruning, E. R.; Kovacic, M. L.; Oberdick, L. E. 1985. Segmentation Analysis of Domestic Airline Passenger Markets, Academy of Marketing Science, Journal of the Academy of Marketing Science Winter 13(1-2): 17-31.

Chao, C. C.; Lirn, T. C.; Shang, K. C. 2013. Market segmentation of airline cargo transport, The Service Industries Journal 33(15-16): 1672-1685.

Chen, F. Y.; Tu, S. L.; Wang, H. E. 2016. Green market segmentation: A caseof airline customers in Taiwan, Journal of Sustainable Development 9(1): 99-109.

Collins, A.; Rose, J. M.; Hess, S. 2010. Interactive stated choice surveys: a study of air travel behaviour, Transportation 39(1): 55-79. 
Doganis, R. 2002. Flying off course: the economics of international airlines. 3rd edition, Abingdon: Routledge, New York City, USA. 345 p.

Freathy, P.; O'Connell, F. 2000. Market segmentation in the European airport sector, Marketing Intelligence \& Planning 18(3): 102-111.

Hair, Jr. J. F.; Black, C.W.; Babin, J.B.; Anderson, E.R. 2014. Multivariate Data Analysi. Seventh Edition, Pearson Education Limited, Edinburgh, England. 734 p.

Hess, S.; Adler, T.; Polak, J. W. 2006. Modelling airport and airline choice behaviour with the use of stated preference survey data, Transportation Research Part E: Logistics and Transportation 43(3): 221-233.

Hess, S. 2008. Treatment of reference alternatives in stated choice surveys for air travel choice behaviour, Journal of Air Transport Management 14(5): 275-279.
Lu, J. L.; Tsai, L. N. 2004. Modeling the Effect of Enlarged Seating Room on Passenger Preferences of Domestic Airlines in Taiwan, Journal of Air Transportation 9(2): 83-96.

Robles, F.; Sarathy, R. 1986. Segmenting the Commuter Aircraft Market with Cluster Analysis, Industrial Marketing Management 15(1): 1-12.

Teichert, T.; Shehu, E.; Wartburg, I. 2008. Customer segmentation revisited: The case of the airline industry, Transportation Research Part A: Policy and Practice 42(1): 227-242. 